\title{
A POBREZA A PARTIR DA PERSPECTIVA NEOLIBERAL E A REALIDADE DA COVID-19
}

\author{
POVERTY ON THE NEOLIBERAL PERSPECTIVE AND THE COVID-19 REALITY
}

\author{
Sandra Eloisa Pisa Bazzanella ${ }^{1}$ \\ https://orcid.org/0000-0002-7037-2139 \\ Alessandro Pinzani² \\ https://orcid.org/0000-0001-8721-2134
}

Recebido em: 11 ago. 2021

Aceito em: 15 out. 2021

\begin{abstract}
Como citar este artigo: PISA BAZZANELLA, S. E.; PINZANI, A. . A POBREZA A PARTIR DA PERSPECTIVA NEOLIBERAL E A REALIDADE DA COVID-19. Revista Visão: Gestão

Organizacional, Caçador (SC), Brasil, v. 10, n. 1, p. 189-202, 2021. DOI:

10.33362/visao.v10i1.2679. Disponível em:

https://periodicos.uniarp.edu.br/index.php/visao/article/view/2679.
\end{abstract}

Resumo: A realidade da pandemia de COVID-19 impactou de maneiras diversas vários países. No Brasil, a suposta dicotomia saúde-economia pautou decisões dos governos, que não obtiveram sucesso em conter casos do novo coronavírus, tampouco em garantir os menores impactos econômicos possíveis. A desigualdade que assola historicamente o país é acompanhada de discursos que se propõem a interpretar a realidade. No âmbito do discurso neoliberal, a partir de conceitos como os de meritocracia e de responsabilidade individual, os indivíduos se identificam como os únicos responsáveis por seu sucesso ou fracasso. A pobreza, neste sentido, consistiria em um aglomerado de fracassos individuais que coincidem numa mesma condição socioeconômica. O objetivo deste trabalho de pesquisa concentra-se no questionamento desta concepção à luz da realidade da COVID-19. Busca-se demonstrar de que modo é construído o discurso neoliberal acerca da pobreza e indagar se este discurso pode ser questionado. O trabalho aponta para o fato de a resposta do governo brasileiro à crise epidêmica ter sido marcada por uma racionalidade neoliberal que aplicou o discurso da individualização e privatização às políticas de saúde pública.

Palavras-Chave: Pobreza. Neoliberalismo. Covid-19.

Abstract: The COVID-19 reality impacted on many countries in different ways. In Brazil, the supposed dichotomy health vs. economy guided the present govern in its decisions, which did not manage to contain the COVID-19 cases, not to minimize their economic impacts. The inequality that historically haunts the country is reinforced by discourses that aim to justify social reality. Following the neoliberal discourse, which use concepts

\footnotetext{
${ }^{1}$ Estudante de Filosofia - Universidade Federal de Santa Catarina. Email: sandra.bazzanella@hotmail.com.

${ }^{2}$ Professor de Ética e Filosofia Política - Universidade Federal de Santa Catarina. Email: alessandro@cfh.ufsc.br.
} 
like meritocracy and individual responsibility, individuals should see themself as the only responsible for their success or failure. In this perspective, poverty result by an set of individuals failures that lead to the same socioeconomic condition. The objective of this paper is to question of this conception in light of the COVID-19 reality. It aims to show how the neoliberal discourse on poverty is constituted and to question it. It points to the fact that the Brazilian government's answer to the epidemic crise has been marked by a neoliberal rationality that applies individualization and privatization discourses to public health policies.

Keywords: Poverty. Neoliberalism. Covid-19.

\section{INTRODUÇÃO}

A pandemia da Covid-19 impactou o mundo de diversas formas. Neste trabalho de pesquisa, busca-se uma interpretação de dados estatísticos acerca do momento pandêmico vivido pelo Brasil para refletir preconcepções acerca da pobreza e de que modo elas apresentam correspondência com a realidade. A importância de tal proposta justifica-se na necessidade de compreensão dos mecanismos e ideologias que são incutidos à sociedade diariamente pelos mais diversos meios de comunicação, bem como compreensão e reconhecimento das limitações da interpretação neoliberal da pobreza perante à atual realidade social em âmbito nacional. Reconhecendo as limitações da interpretação neoliberal da pobreza, se podem articular interpretações que correspondam de forma mais adequada aos desafios de compreensão da realidade, de forma a situar perspectivas analíticas mais consistentes acerca da pobreza que represente as inúmeras variáveis constitutivas deste fenômeno. Esta discussão poderá ser realizada de forma suficiente após conhecer-se estas preconcepções confrontadas a dados que auxiliem a pesquisa. Inicia-se, portanto, pela compreensão da interpretação da pobreza via discurso neoliberal.

Utilizar-se-á aqui duas abordagens para conceituar o neoliberalismo. A primeira é de Vivian Domínguez Ugá3. A segunda parte de Dardot e Laval, que oferecem uma visão foucaultiana sobre o neoliberalismo4.

\footnotetext{
${ }^{3}$ As abordagens de Ugá serão utilizadas ao longo de todo este trabalho. A cientista política apresentou em sua tese de doutorado, transformada posteriormente no livro A questão social como "pobreza": crítica à conceituação neoliberal, abordagens aqui utilizadas para compreender a visão neoliberal da pobreza.

${ }^{4}$ Dardot e Laval são influenciados sobretudo por Michel Foucault (1926 - 1984). O pensador apresenta em sua obra O Nascimento da Biopolítica a abordagem do neoliberalismo a partir da perspectiva genealógica. Buscando estabelecer uma historiografia, na medida em que compreende a natureza do liberalismo, Foucault apresenta-o como uma racionalidade. Para Foucault, não se tratava de compreender o liberalismo ou o neoliberalismo em suas vertentes econômicas, mas compreender de que modo, sobretudo o neoliberalismo, se conformaria como uma prática de governo e gestão da vida.
} 


\section{METODOLOGIA}

A metodologia utilizada nesta pesquisa consiste na pesquisa documental e bibliográfica em sites da internet, artigos científicos e livros.

\section{NEOLIBERALISMO COM RACIONALIDADE}

Pierre Dardot e Christian Laval, em sua obra: A nova razão do mundo (2016) apresentam o neoliberalismo como racionalidade. O neoliberalismo, do modo como apresentado pelos autores, surge no contexto da crise do liberalismo. ${ }^{5}$ Crise esta cujo período identifica-se entre os anos de 1880 e 1930 e demonstrou as limitações do liberalismo clássico na compreensão dos movimentos do capitalismo. Duas são as respostas à crise, identificadas pelos autores. Uma parte do "novo liberalismo" e outra do "neoliberalismo" (DARDOT, LAVAL, 2016, p. 68). Talvez o principal ponto de discordância dessas correntes esteja no modo como encaram a interferência estatal. Ainda que ambos compreendam a necessidade da interferência, a divergência encontra-se no fato de o novo liberalismo admitir a utilização de técnicas que interfiram nos interesses individuais com a finalidade de garantir as condições para a existência do liberalismo, enquanto o neoliberalismo não aceita essa interferência nos interesses privados.

O termo "racionalidade" é empregado em relação ao neoliberalismo não apenas por Dardot e Laval, mas também, e primeiramente, por Foucault. Introduzir o neoliberalismo como racionalidade, portanto, significa dizer que ele mesmo apresenta uma razão sob a qual baseiam-se os movimentos governamentais: "O neoliberalismo é a razão do capitalismo contemporâneo" (DARDOT, LAVAL, 2014, p. 17). Deste modo, oferece os parâmetros sob os quais estruturam-se as relações de poder e práticas governamentais. A principal vertente do neoliberalismo como racionalidade, portanto, pode ser identificada como a generalização da concorrência nas relações de trabalho e a introdução desta noção na vida privada dos trabalhadores, ou sujeitos neoliberais.

É neste sentido que o neoliberalismo também atua na construção das subjetividades, de homens empresariais, nos termos de Dardot e Laval. A conformação do sujeito neoliberal ocorre de modo a introduzi-lo a concepções como a de empreendedorismo. No ambiente da dinâmica produtiva, o empreendedorismo passa a ser valorizado não apenas como prática necessária aos empresários, mas aos funcionários, que admitindo a lógica empreendedora em suas vidas não restringem suas contribuições ao âmbito da empresa, mas também, e sobretudo, ampliam o empreendedorismo à esfera individual, tornando-se gestores do próprio

\footnotetext{
5 Para uma história intelectual e política do neoliberalismo ver, entre outros, MIROWSKI; PLEHWE 2009 e STEDMAN JONES 2012.
} 
sucesso. É nesta direção que a lógica da competição atua conjuntamente do empreendedorismo:

(...) a racionalidade neoliberal produz o sujeito que necessita ordenando os meios de governá-lo para que ele se conduza realmente como uma entidade em competição e que, por isso, deve maximizar seus resultados, expondo-se a riscos e assumindo inteira responsabilidade por eventuais fracassos. (DARDOT; LAVAL, 2014, p. 328)

Ao passo que integram os movimentos do mercado a partir da lógica de empreendimento e competição, os sujeitos criam eles mesmos novas condições de trabalho e de vida:

(...) a novidade consiste em promover uma "reação em cadeia", produzindo "sujeitos empreendedores" que, por sua vez, reproduzirão, ampliarão e reforçarão as relações de competição entre eles, o que exigirá, segundo a lógica do processo autorrealizador, que eles se adaptem subjetivamente às condições cada vez mais duras que eles mesmos produziram. (DARDOT; LAVAL, 2014, p. 329)

É neste sentido que o processo de subjetivação no neoliberalismo atua: de modo a introduzir nos sujeitos a responsabilidade pela sua autogestão enquanto empresários de si mesmos; e a responsabilidade pelo seu sucesso ou fracasso, enquanto competidores participantes de uma sociedade baseada na concorrência. ${ }^{6}$

\section{A POBREZA NA PERSPECTIVA NEOLIBERAL}

Vivian Domínguez Ugá apresenta, no capítulo 2 de sua obra, concepções que nos auxiliam a compreender o neoliberalismo. A autora apresenta, inicialmente a proposta de Friedrich Hayek, tido como o pai do neoliberalismo. Para o autor tratava-se de promover a liberdade individual, pois, agindo espontaneamente no mercado, "os indivíduos acabam, sem perceber, produzindo o melhor resultado possível para a sociedade como um todo" (UGÁ, 2011, p. 75). Neste sentido, a responsabilidade individual permeia as relações, e é a ela que se recorre em casos de pobreza, desemprego, inexpressivo sucesso profissional ou financeiro.

Milton Friedman, no mesmo caminho, apresenta-se como defensor da liberdade e, sobretudo, responsabilidade individual, opondo-se à saída da pobreza por meio única e exclusivamente de programas sociais do governo. Ele admite o auxílio do Estado em casos temporários de pobreza, ao passo que defende a caridade privada como meio de intervenção.

\footnotetext{
${ }^{6}$ Entretanto, não é apenas com o neoliberalismo que os sujeitos passam a ser encarados a partir das possibilidades de otimização de suas capacidades produtivas. O utilitarismo de Jeremy Bentham, na figura central do panóptico, visava, já no século XIX o controle e a disciplina sobre os corpos, conformados na docilidade e agilidade para o trabalho e para o consumo (DARDOT; LAVAL, 2014). Foucault, nesta direção, designou o conjunto de técnicas incidentes sobre os corpos de biopoder. Atuante tanto na dimensão corporal individual quanto na dimensão do controle populacional, o biopoder inaugura, a partir do século XVII, um modo de controle da vida baseado na utilidade e no controle dos corpos para a sujeição ao trabalho. Uma das novidades do neoliberalismo em relação ao biopoder é fazer com que os movimentos de aperfeiçoamento e competição não se deem por coação do poder soberano, mas por movimentos aparentemente naturais das dinâmicas do mercado.
} 
O que importa destacar, em relação ao pensamento neoliberal, de toda forma, é:

(...) a defesa da redução do Estado - conservando, entretanto, seu papel de garantidor da propriedade privada e do cumprimento dos contratos -, em oposição à intervenção estatal, e da ideia de "mercado" como o melhor organizador das relações sociais e o único capaz de promover a plena liberdade do indivíduo (UGÁ, 2011, p. 85)

A seguir continua-se com Ugá, buscando de que modo é possível compreender a pobreza na perspectiva neoliberal. Ela analisa parte dos documentos elaborados por organismos internacionais, e afirma:

(...) a retórica internacional sobre a pobreza, longe de representar mudanças, compartilha os fundamentos ideológicos das estratégias neoliberais. Ou seja, o mundo social pressuposto pelo tratamento da questão social a partir do conceito de "pobreza" é justamente o mundo social característico do neoliberalismo. Embora os organismos internacionais se preocupem em tratar do humano e do social em suas propostas de políticas de "desenvolvimento", é preciso distinguir bem em que consiste esse "humano" e "social" (UGÁ, 2011, p.183)

Deste modo, partindo do pressuposto de que os organismos internacionais se apresentam como reprodutores, em certa medida, de um discurso neoliberal, é necessário analisá-los. Ugá apresenta as concepções do Banco Mundial, do PNUD e da Organização Internacional do Trabalho. Posteriormente, apresenta quais os tratamentos possíveis propostos pelos organismos internacionais à pobreza. Aqui aborda-se especificamente a designação de "pobreza" desenvolvida.

Inicia-se analisando o Banco Mundial. O Relatório sobre Desenvolvimento Mundial de 1990, intitulado: A Pobreza, elaborado pelo Banco Mundial, é interpretado por Ugá como definindo a pobreza como "a incapacidade de atingir um padrão de vida mínimo" (WORLD BANK, 1990, p. 1, apud UGÁ, 2011, p. 187). A explicação encontrada para a pobreza, neste sentido, diria respeito a duas questões: a falta de ativos e a falta de oportunidades. Os dois ativos mais importantes segundo Ugá são o capital humano (necessário em áreas urbanas) e a terra (necessária em áreas rurais). Sem ativos, os indivíduos encontram dificuldades para conseguir oportunidades que lhes façam sair da linha da pobreza.

O PNUD, Programa das Nações Unidas para o Desenvolvimento, recorre à noção de "desenvolvimento humano", sobretudo aquele definido por Amartya Sen, para oferecer um tratamento à pobreza. O fenômeno, neste sentido, seria caracterizado como "a negação das oportunidades e escolhas mais elementares para desenvolvimento humano" (UGÁ, 2011, p. 223). Ainda: "Dentro da perspectiva proposta pelo PNUD (...) o pobre aparece como um indivíduo "sem capacidades", sem "condição de agência", carente de oportunidades e de escolhas em sua vida" (UGÁ, 2011, p. 226).

A Organização Internacional do Trabalho, embora não ofereça definições precisas, segundo Ugá, se põe perante à questão da pobreza relacionando-a com a produtividade. A 
produtividade seria uma forma de prover ao trabalhador maiores salários, ao passo que geraria, para a empresa, menores custos de produção. O aumento da produtividade se apresentaria como feliz novidade não só em relação ao "trabalhador pobre", na medida em que pode aumentar sua remuneração, mas também em relação ao desemprego, que poderia ser diminuído a partir da associação da produtividade com o "capital humano" (UGÁ, 2011).

A crítica de Ugá, neste sentido, dá-se, num primeiro momento, pela enunciação e redução da questão social à noção de "pobreza". Posteriormente, é necessário reconhecer que esta enunciação parte dos organismos internacionais: "porta-vozes da globalização" (UGÁ, 2011, p. 170).

Estas compreensões apresentam-se a partir de organismos internacionais. É importante considerar tais compreensões, ao passo que também se busca compreender certas tentativas de definições correntes no discurso popular. Isto pois, embora as questões apresentadas pela OIT, PNUD e Banco Mundial, possam influenciar políticas sociais de governos mundo afora, o cotidiano brasileiro é perpassado por uma série de preconcepções acerca da pobreza. O que Adorno chamaria de "ideologia" é incutido à população diariamente por meios que ele chamaria de "indústria cultural"7. Não é suficiente, portanto, recorrer apenas às organizações internacionais, é possível, inclusive, analisar o discurso corrente que advém, também, mas não apenas, a partir das concepções apresentadas.

O naturalismo social malthusiano representa outra premissa implícita das posições defendidas por autores neoliberais (PINZANI 2017). A concepção malthusiana, sucintamente, apresenta a necessidade da não intervenção externa na pobreza, uma vez que os pobres, recebendo auxílios de quaisquer esferas sociais acabariam por perpetuar a pobreza, gerando mais descendentes e mantendo-se acomodados a sua situação. Sem intervenção externa, a sociedade se autorregularia, e os pobres se tornariam cada vez menos numerosos, pois sem condições de sustentarem-se a si mesmos, não gerariam descendentes.

Na esteira da ideia de responsabilização individual, ainda em Ugá:

Apenas os indivíduos podem, para Hayek (1977), ser julgados moralmente e, por conseguinte, ser responsabilizados. Se alguém está desempregado ou é miserável não pode ser visto como culpa do sistema, mas sim de sua falta de destreza, esforço ou, ainda, sorte. A responsabilidade é, portanto, individual, e não social (UGÁ, 2011. p. 78)

É possível recorrer, ainda, a jargões e preconcepções que perpassam o cotidiano. Destaca-se, neste sentido, o constante incentivo ao aperfeiçoamento individual como forma

\footnotetext{
${ }^{7}$ Adorno interpreta a ideologia como inerente às sociedades modernas, atuando não apenas na dimensão objetiva, mas também subjetiva, sendo responsável por criar e direcionar tendências de pensamento nos indivíduos de maneira a conformar uma opinião comum. A indústria cultural, por sua vez, é composta pelos meios de comunicação, jornais, rádios, televisões, ou mesmo a publicidade. Ela é estreitamente ligada à ideologia, uma vez que é por meio dela que a ideologia adentra o imaginário social.
} 
de ascensão social. Isto é, você precisa investir em si mesmo, investir no seu capital humano, para que corresponda às necessidades do mercado de trabalho. Se com uma especialização, por exemplo, você não consegue emprego, então urge a necessidade de um investimento maior, uma vez que alguém mais capacitado que você ocupou o lugar pretendido.

Neste sentido, evidentemente todos são concorrentes, e o sucesso, ou fracasso, são delimitados por escolhas individuais. E o que ocorre quando se ocupam posições distintas? Quando alguém é um trabalhador braçal e outro alguém é um empresário de sucesso? Poderse-ia dizer que o trabalhador braçal, ao longo de sua vida, teve preguiça de investir em si mesmo e apenas por isso não é um empresário de sucesso? Mas o empresário de sucesso cursou Administração de Empresas e abriu seu negócio. Hoje faz sucesso. Todas as outras pessoas que cursaram Administração de Empresas e não obtiveram sucesso em abrir um negócio, tornando-se assalariadas e submissas a um patrão então não se esforçaram o suficiente para ascenderem socialmente?

É necessário chamar atenção para tais concepções e, mais que isso, questionar se podem ser tomadas como regra. Isto porque o Brasil sobretudo no último ano, tem vivido períodos de instabilidade socioeconômica, e encontrar na esfera individual a única responsabilidade pelas precárias situações enfrentadas pelos indivíduos que se somam em milhões de pessoas não parece um caminho sadio para compreender as contradições presentes no contexto social brasileiro.

\section{PANDEMIA E RACIONALIDADE NEOLIBERAL NO BRASIL}

Vivian Domínguez Ugá apresenta, A pandemia do novo coronavírus foi assim classificada pela OMS em março do ano passado. No mesmo período iniciavam as infecções pelo Brasil. Num curto período de tempo autoridades passaram a discutir meios para contenção do contágio, meios estes que envolviam lockdown, fechamento do comércio e até mesmo de fronteiras entre os municípios. Consequentemente, estas medidas influenciaram milhares, se não milhões de famílias, que viram algum ou alguns de seus membros perderem a renda por uma série de motivos.

Ainda em março de 2020, o ministério da economia estudava um auxílio aos trabalhadores informais, e chegou a declarar o valor pretendido: $\mathrm{R} \$ 200,00$ reais. Em 30 de março a Câmara dos Deputados votou um novo valor para o auxílio emergencial: $R \$ 600,00$ reais, e a proposta foi sancionada em 2 de abril, mesmo com vetos, virando lei. ${ }^{8}$

Segundo dados do IBGE, o desemprego atingiu a marca de $14,7 \%$ no primeiro trimestre de 2021, contabilizando cerca de 14,8 milhões de desempregados. O que deve ser analisado,

\footnotetext{
$8 \quad$ Fonte: https://www12.senado.leg.br/noticias/materias/2020/12/30/aprovado-pelo-congresso-auxilioemergencial-deu-dignidade-a-cidadaos-durante-a-pandemia
} 
de todo modo, não é apenas a taxa de desemprego, mas também a de pessoas desalentadas, isto é, pessoas que pararam de procurar emprego. Hoje, no Brasil, o percentual soma cerca de 6 milhões de pessoas

Pensando nos futuros trabalhadores, se deve analisar alguns dados sobre a condição da educação no contexto pandêmico. Um estudo do UNICEF (Fundo das Nações Unidas para a Infância) em parceria com o CENPEC (Centro de Estudos em Pesquisas em Educação, Cultura e Ação Comunitária), intitulado Cenário da Exclusão Escolar no Brasil - um Alerta sobre os Impactos da Pandemia da Covid-19 na Educação, dá conta de que no último ano cerca de 5 milhões de crianças e adolescentes com idade entre 6 e 17 anos "estavam fora da escola ou sem atividades escolares" (CENPEC; UNICEF, 2021, p. 44).

Após esses dados, que poderiam ser aprofundados e analisados a partir de inúmeras variáveis, e após as concepções já apresentadas acerca da pobreza, algumas considerações devem ser feitas. Se considerados os impactos econômicos gerados pela pandemia da Covid19, neste caso no Brasil, com a diminuição de postos de trabalho, alta do desemprego e desalento, seria possível afirmar que todos os pobres e desempregados assim o são apenas porque não apresentam as características que o mercado precisa, ou requer? Que características seriam essas? Seria possível afirmar que os pobres e desempregados assim o são apenas porque não investiram no seu capital humano?

O que se dirá, então, das crianças e adolescentes, que afastados das escolas podem perder não apenas os conhecimentos necessários para sua formação, mas o ano letivo e, consequentemente, deixarem de desenvolver habilidades necessárias ao mercado de trabalho? Deixarem de obter até mesmo um diploma. A falta de condições de acesso de muitas dessas crianças, não deve ser levada em conta quando tornarem-se adultas e, quiçá, não tiverem desenvolvido as habilidades que eram supostas serem desenvolvidas na idade correta?

Propõe-se a seguir um modo de compreender a forma como a esfera individual foi enfatizada no combate à pandemia e, consequentemente, nos impactos socioeconômicos desta crise. Para isto serão pautados dois eixos que parecem influenciar a direção tomada pelo Brasil, sobretudo no último ano. Não se trata de aspectos novos na realidade brasileira, tampouco surgidos com a pandemia, mas sim, aspectos constitutivos da realidade nacional que se tornaram particularmente evidentes a partir de 2020.

O primeiro eixo diz respeito a um caráter privatista presente na racionalidade governamental brasileira. Exemplo disso é o projeto de lei número 948/2021 que dispõe sobre a compra de vacinas pela iniciativa privada. O texto-base do projeto foi aprovado pela Câmara dos Deputados em abril e encaminhado ao Senado Federal. Não há notícias de que medidas como esta tenham sido adotadas nos Estados Unidos ou na Inglaterra, por exemplo, países conhecidos pela forte influência dos preceitos neoliberais em seus governos. Por outro lado, países como Indonésia, Filipinas, Paquistão e Índia, cada qual com suas especificidades, 
permitiram que a iniciativa privada estivesse envolvida na compra de vacinas.

Mais do que incidir sobre aspectos econômicos, a proposição e consideração da presença da iniciativa privada na corrida pela imunização aponta para uma racionalidade individualizante e para uma forte confiança no mercado como instrumento de resolução de problemas sociais, inclusive no caso de crises epidemiológicas. Admite-se que empresários com poder aquisitivo suficiente adquiram vacinas para si mesmos e seus funcionários, em contraste com a impossibilidade de empresários menores atuarem do mesmo modo e, consequentemente, lidarem com menor risco de paralização da produção por conta das consequências de um possível contágio entre os funcionários. Enquanto pessoas com alto poder aquisitivo poderiam optar por buscar a imunização no sistema de saúde público ou no sistema particular, pessoas com baixo poder aquisitivo seriam obrigadas a competir pelos escassos recursos do sistema público que, por sua vez, deveria competir pelas vacinas com o sistema particular, que dispõe de recursos financeiros bem maiores.

Outro ponto a ser considerado na possibilidade de privatização da compra de vacinas diz respeito ao enfraquecimento do Sistema Único de Saúde. Uma vez que o Brasil é referência mundial em vacinação, o fortalecimento do SUS permitiria que a vacinação em massa contra a Covid-19 incidisse sobre os brasileiros a partir de critérios estabelecidos pelo Plano Nacional de Imunização (como fator de risco, idade, etc.), e não a partir de critérios econômicos, como seria o caso da compra de vacinas pela iniciativa privada. A proposição da participação privada na imunização, portanto, aponta também para a escolha deliberada de beneficiamento dos empresários com poder aquisitivo - o que poderia beneficiar alguns membros da iniciativa privada, sejam empresários ou empregados - em detrimento da contribuição para um sistema que abrange todos os brasileiros, independentemente de suas condições socioeconômicas.

Pode-se associar à racionalidade individualizante um segundo eixo: o econômico. Ao longo da pandemia da Covid-19, um dos discursos vigentes no plano econômico dizia respeito à necessidade de não endividamento do país ao longo deste período. Embora países mundo afora tenham endividado a si mesmos para garantir um controle eficiente do contágio e, assim fazer com que medidas como lockdown não fossem necessárias por um longo período, o Brasil optou pela garantia de um auxílio emergencial deficitário e pela tentativa de não paralização das atividades econômicas exercidas de modo presencial. Ao mesmo tempo em que o governo do Brasil não pode endividar-se, já que a constituição proíbe isso, a dívida das Igrejas em relação a Imposto de Renda e INSS, no valor de 1,4 bilhão de reais, foi perdoada em 2021 sem nenhuma justificativa válida.

No sentido de buscar compreender os desdobramentos na área da saúde a partir dos dois eixos citados, é importante considerar uma variável: a debilidade do Estado nos países da América do Sul. A região historicamente vê-se refém das elites nacionais e internacionais que não hesitam em golpear as frágeis democracias sul-americanas a fim de conformarem estados 
que Ihes ofereçam condições propícias ao aumento de seu poder. O resultado desta herança são estados que não contam com sólidas estruturas e instituições legitimadas a tomarem a frente de certos setores em momentos como o da pandemia da Covid-19. No caso do Brasil, a expertise dos técnicos do Sistema Único de Saúde e do Ministério da Saúde, foi substituída por posições ideológicas acerca das questões de saúde pública.

Do ponto de vista material, o enfraquecimento do Estado brasileiro identifica-se na falta de sucesso de um programa de testagem em massa da população, associado a programas de controle e monitoramento de possíveis contaminados. Se poderia mencionar, além disso, a descentralização das medidas de prevenção do contágio, representada pela decisão do Supremo Tribunal Federal de abril de 2020, que atestou que estados e municípios também possuíam autonomia sobre decisões relacionadas à Covid-19. Mais do que dar-se como ação que respeita o caráter tripartite do SUS, esta decisão representa a dificuldade de coordenação, a nível nacional, de combate a um risco descoberto recentemente e sobre o qual o conhecimento científico era (e ainda é) limitado.

A partir dos dois eixos - o do discurso econômico e o do discurso neoliberal individualizante - e desta variável a nível geopolítico, é possível compreender de que modo a gestão da saúde no Brasil ao longo da pandemia da Covid-19 foi pautada por uma racionalidade, sobretudo, neoliberal. Neoliberal pois a nível discursivo buscou eximir o Estado de suas responsabilidades para com os cidadãos no sentido da prevenção; neoliberal também a nível econômico, pois eximiu-se da responsabilidade de garantir aos trabalhadores, micro e pequenos empresários, meios de sobrevivência suficientes durante um período de movimento econômico reduzido. Associada esta cartilha neoliberal à histórica deficiência estrutural do Estado em garantir acesso à saúde (também à educação, moradia, saneamento básico, segurança) de qualidade, os caminhos da responsabilização individual no cuidado com a saúde parecem desenhados.

Poder-se-ia adicionar a este caminho discursos ideológicos que relativizaram medidas de proteção e, deste modo, deslegitimaram o uso de máscaras e a prática do distanciamento social, convencionados mundialmente por autoridades sanitárias como meios efetivos para controle da disseminação do vírus.

Abordando-se a temática da pobreza no contexto da pandemia da Covid-19, aos dois eixos mencionados acima deve ser adicionada uma variável histórica. É a relação entre a sociedade brasileira e a pobreza. Esta relação remonta desde os tempos da chegada dos portugueses às terras hoje brasileiras, enfatizando-se o papel da escravidão na construção no ethos popular. A mentalidade que pauta a inferioridade dos povos negros e indígenas não se restringiu ao período escravocrata. Após o fim da escravidão, em 1888, os então ex-escravos, sem quaisquer bens próprios, viram-se relegados à própria sorte para buscarem meios de sobrevivência. Parte dos que conseguiam deixar o domínio de seus senhores concentrou-se nas 
periferias das cidades, sem contar com infraestrutura ou quaisquer tipos de auxílio para estabelecer-se de forma digna em uma propriedade.

De lá até hoje pouca coisa mudou, se não a multiplicação das faces da pobreza no Brasil. O pobre continua a ser visto como um sujeito inferior aos demais cidadãos, quando não alvo de preconceitos de toda ordem. Os projetos políticos que ascenderam ao poder não têm dado, em sua maioria, atenção especial ao fenômeno da pobreza, reproduzindo, se não contribuindo para o aumento das desigualdades sociais. Embora a adesão à sistemas de cotas raciais e socioeconômicas e programas de auxílios das mais diversas variáveis apresentem-se como importantes aliados ao combate e ao tratamento da pobreza, a limitação destas iniciativas à questões pontuais promove uma lenta progressão socioeconômica entre as camadas populares. Quando os programas de auxílio são cortados, ou seus orçamentos reduzidos à valores ínfimos, as previsões de progresso são anuladas e a ascensão socioeconômica volta a ser de responsabilidade unicamente individual.

No âmbito da opinião pública, chama-se atenção para um conceito desenvolvido por Adela Cortina, filósofa espanhola: aporofobia: “Del gr. őrropos áporos 'carente de recursos' y fobia", como ressalta a definição da Real Academia Espanhola. Identifica-se, deste modo, a aporofobia como a rejeição, medo, fobia, a pessoas pobres, socioeconomicamente vulneráveis:

\footnotetext{
Se há um incômodo global com o outro, este outro é o pobre, o miserável, aquele que a maioria deseja invisível, conforme Adela Cortina ressalta; um incômodo que difere da xenofobia e do racismo. Olhar para este outro significa ver onde erramos, onde continuamos a errar por não ver e para não agir. (TORRACA, 2020, p. 1)
}

Deste modo, ao passo que a realidade da pobreza se apresenta como necessariamente visível, seja nas comunidades, nos semáforos, nas assistências sociais, ela torna-se incômoda. Também por demonstrar aspectos da realidade do país, mas principalmente porque aponta que como sociedade o Brasil ainda é constituído sobre as bases da desigualdade social.

Associando-se esta realidade ao primeiro eixo, o da individualização, se não privatização da sobrevivência, as saídas para os pobres parecem encontrarem-se na ascensão por meio de empregos, o que apresenta inúmeros obstáculos vide o número de desempregados e desalentados. As camadas vulneráveis socioeconomicamente possuem dificuldades de inserirem-se no mercado de trabalho formal visto a necessidade cada vez maior de certas qualificações que não são prioridade de pessoas que por vezes possuem dificuldades financeiras para a satisfação de necessidades básicas.

Neste sentido, ao responsabilizar as escolhas individuais das pessoas pobres, torna-se desnecessária a autocrítica como sociedade, a reflexão e o questionamento sobre os aparatos que auxiliam na manutenção da pobreza. Cobre-se parte do problema para afastá-lo das responsabilidades que a sociedade brasileira historicamente possui, atribuindo aos indivíduos os méritos ou dissabores de suas trajetórias pessoais. A sociedade brasileira, portanto, exime- 
se de seu papel e volta-se contra um problema que não pode e não é apenas individual, mas sobretudo social.

O que buscou-se demonstrar com os dados oferecidos acima é que a realidade suscitada pela pandemia da Covid-19 torna evidente o que busca-se camuflar: a pobreza no Brasil não é um fenômeno individual e não diz respeito apenas à má vontade dos indivíduos de tornaremse empresários de si mesmos, de gerirem seu capital humano de forma a obterem lucro a partir das próprias habilidades.

\section{CONSIDERAÇÕES FINAIS}

A partir do exposto, é possível compreender de que modo a gestão da saúde no decorrer da pandemia da Covid-19 foi pautada sob preceitos neoliberais. Preceitos estes que participam de tomadas de decisões na esfera econômica e da conformação de discursos individualizantes na esfera pública. O cuidado de si foi direcionado à esfera privada da vida, ao passo que interpretações neoliberais da pobreza permitem compreendê-la como fenômeno individual. Há, neste sentido, a possibilidade de os impactos socioeconômicos no Brasil serem reduzidos à responsabilidade dos indivíduos, e não de estruturas que contribuem para a manutenção da desigualdade social, evidenciada pela pandemia.

Identifica-se ao longo desta pesquisa a necessidade de um aprofundamento na compreensão da pobreza como fenômeno que atinge milhões de brasileiros em diferentes partes deste país continental. Isto pois, a partir do exposto, não é suficiente compreender a pobreza apressadamente como um conjunto de falhas individuais. Este aprofundamento, por sua vez, é necessário e urgente, pois os pré-conceitos explícitos ou implícitos no imaginário social brasileiro podem, por vezes, ser carregados de generalizações apressadas, envolvendo meritocracia, capital humano, e outros bordões empregados na tentativa de reduzir as dinâmicas socioeconômicas à dimensão e responsabilidade individuais. Este aprofundamento justifica-se necessário, por fim, pois um país que não consegue reconhecer a si mesmo, em suas falhas, contradições, desafios, e sua própria história, apresenta dificuldade em compreender os caminhos para seu desenvolvimento.

\section{REFERÊNCIAS}

APOROFOBIA. Real Academia Espanhola. Disponível em <https://dle.rae.es/aporofobia> Acesso em 29 de julho de 2021.

Bolsonaro volta atrás e perdoa dívida de R\$1,4 bilhão de igrejas. Estado de Minas. 18 de mar. de 2021. Disponível em

<https://www.em.com.br/app/noticia/politica/2021/03/18/interna_politica,1248010/bolsona ro-volta-atras-e-perdoa-divida-de-r-1-4-bilhao-de-igrejas.shtml> Acesso em 09 de agosto de 
2021.

CENPEC; UNICEF. Cenário da Educação Escolar no Brasil - Um alerta sobre os impactos da pandemia da COVID-19 na Educação. Abril, 2021.

DARDOT, Pierre. LAVAL. Christian. A nova razão do mundo: ensaio sobre a sociedade neoliberal. Tradução: Mariana Echalar. $1^{0}$ edição. São Paulo: Boitempo, 2016.

FERGUSON, James. The uses of Neoliberalism. Antipode. Vol 41, N S1 2009. p. $166-184$.

FOUCAULT, Michel. Nascimento da Biopolítica. Tradução: Eduardo Brandão. $1^{0}$ edição. São Paulo: Martins Fontes, 2008.

Desemprego. IBGE, Instituto Brasileiro de Geografia e Estatística. Disponível em < https://www.ibge.gov.br/explica/desemprego.php> Acesso em 03 de agosto de 2021.

LUIZ, Felipe. Governo e Mercado: Foucault e a Emergência do Neoliberalismo Alemão. Humanidades em diálogo. Vol IV, N II. p. $155-170$.

MIROWSKI, Philip; PLEHWE, Dieter (eds.). The Road from Mount Pèlerin. The Making of the Neoliberal Thought Collective. Cambridge (MA): Harvard University Press, 2009.

PINZANI, Alessandro. "Vai trabalhar, vagabundo": retórica antipobre e aspectos normativos de uma teoria da pobreza. In: SILVA, Helio Alexandre da (org.). Sob os olhos da crítica:

reflexões sobre democracia, capitalismo e movimentos sociais. Macapá: UNIFAP, 2017. p. 348 $-388$.

PL948/2021. Câmara dos Deputados. Disponível em $<$ https://www.camara.leg.br/proposicoesWeb/fichadetramitacao?idProposicao=22742 04 > Acesso em 28 de julho de 2021.

POZZEBOM, Eliana Rodrigues. Aprovado pelo Congresso, auxílio emergencial deu dignidade a cidadãos durante a pandemia. Senado Notícias, 2020. Disponível em < https://www12.senado.leg.br/noticias/materias/2020/12/30/aprovado-pelo-congressoauxilio-emergencial-deu-dignidade-a-cidadaos-durante-a-pandemia $>$. Acesso em 15 de junho de 2021.

STEDMAN JONES, Daniel. Masters of the Universe. Hayek, Friedman, and the Birth of Neoliberal Politics. Princeton: Princeton University Press, 2012.

TOMAZELLI, Idiana. Dívida de igrejas com Imposto de Renda e INSS chegam a R\$ 1,9 bilhão. CNN Brasil, 05 abr 2021. Disponível em < https://www.cnnbrasil.com.br/business/2021/04/05/dividas-de-igrejas-com-inss-eimposto-de-renda-ja-chegam-a-r-1-9-bilhao> Acesso em 28 de julho de 2021.

TORRACA, Lia Beatriz Teixeira. Resenha do livro Aporofobia, el rechazo al pobre, de Adela Cortina. Revista da Associação dos Antigos Alunos de Direito da Universidade Federal do Rio de Janeiro, vol. 1, nº 1, 2020, jan./jul., p. 92. 
UGÁ. Vivian Domínguez. A questão social como "pobreza": crítica à conceituação neoliberal. $1^{0}$ edição. Curitiba: Appris, 2011.

VIDALE. Giulia. Os países que liberaram a compra de vacinas pela iniciativa privada. Veja, 10 abr 2021. Disponível em <https://veja.abril.com.br/saude/os-paises-que-liberaram-acompra-de-vacinas-pela-iniciativa-privada/> Acesso em 28 de julho de 2021. 